\title{
BMI open Is socioeconomic status associated with dietary sodium intake in Australian children? A cross-sectional study
}

\author{
Carley A Grimes, Karen J Campbell, Lynn J Riddell, Caryl A Nowson
}

To cite: Grimes CA, Campbell KJ, Riddell LJ, et al. Is socioeconomic status associated with dietary sodium intake in Australian children? A cross-sectional study. BMJ Open 2013;3: e002106. doi:10.1136/ bmjopen-2012-002106

- Prepublication history for this paper are available online. To view these files please visit the journal online (http://dx.doi.org/10.1136/ bmjopen-2012-002106).

Received 27 September 2012 Revised 16 January 2013 Accepted 17 January 2013

This final article is available for use under the terms of the Creative Commons Attribution Non-Commercial 2.0 Licence; see http://bmjopen.bmj.com

Centre for Physical Activity and Nutrition Research, School of Exercise and Nutrition Sciences, Deakin University, Burwood, Victoria, Australia

Correspondence to Ms Carley A Grimes; carley.grimes@deakin.edu.au

\section{ABSTRACT}

Objective: To assess the association between socioeconomic status (SES) and dietary sodium intake, and to identify if the major dietary sources of sodium differ by socioeconomic group in a nationally representative sample of Australian children.

Design: Cross-sectional survey.

Setting: 2007 Australian National Children's Nutrition and Physical Activity Survey.

Participants: A total of 4487 children aged 2-16 years completed all components of the survey.

Primary and secondary outcome measures:

Sodium intake was determined via one $24 \mathrm{~h}$ dietary recall. The population proportion formula was used to identify the major sources of dietary salt. SES was defined by the level of education attained by the primary carer. In addition, parental income was used as a secondary indicator of SES.

Results: Dietary sodium intake of children of low SES background was 2576 (SEM 42) mg/day (salt equivalent $6.6(0.1) \mathrm{g} / \mathrm{day})$, which was greater than that of children of high SES background 2370 (35) $\mathrm{mg} / \mathrm{day}$ (salt $6.1(0.1) \mathrm{g} /$ day; $p<0.001)$. After adjustment for age, gender, energy intake and body mass index, low SES children consumed $195 \mathrm{mg} /$ day (salt $0.5 \mathrm{~g} /$ day) more sodium than high SES children $(p<0.001)$. Low SES children had a greater intake of sodium from processed meat, gravies/sauces, pastries, breakfast cereals, potatoes and potato snacks (all $p<0.05$ ).

Conclusions: Australian children from a low SES background have on average a $9 \%$ greater intake of sodium from food sources compared with those from a high SES background. Understanding the socioeconomic patterning of salt intake during childhood should be considered in interventions to reduce cardiovascular disease.

\section{INTRODUCTION}

As in adults, ${ }^{1}$ dietary sodium intake is positively associated with blood pressure in children. $^{2}{ }^{3}$ Comparable to other developed nations, ${ }^{4}$ the dietary sodium intake of Australian children is high and exceeds dietary recommendations. ${ }^{5} 6$ Given that blood pressure follows a tracking pattern over the life course, ${ }^{7} 8$ it is very likely that

\section{ARTICLE SUMMARY}

Article focus

- To assess the association between socioeconomic status (SES) and dietary sodium intake in Australian children and adolescents.

- To determine if the major dietary sources of sodium differ by socioeconomic group.

Key messages

- In Australian children, SES is inversely associated with dietary sodium intake.

- Children of low socioeconomic background consumed more sodium from convenience style foods including pies/sausage rolls; savoury sauces, fried prepared potato; processed meat and potato crisps.

Strengths and limitations of this study

- These results are based on a large nationally representative sample of Australian children and adolescents.

- Sodium intake was determined via a $24 \mathrm{~h}$ dietary recall and therefore does not capture the amount of sodium derived from salt used at the table or during cooking.

- The socioeconomic disparity of sodium intake reported in this study is attributable to differences in sodium intake from food sources only. Further research is required to understand how SES impacts on raising sodium intake.

high sodium consumption during childhood increases future risk of adult hypertension and subsequent cardiovascular disease (CVD). Increased CVD risk is also observed with low socioeconomic status (SES), ${ }^{9} 10$ potentially due in part to differences in dietary intake. Furthermore, prolonged inequalities of SES across the life course are likely to accumulate to overall greater CVD risk, ${ }^{11}{ }^{12}$ A number of studies in adults ${ }^{13-15}$ and in children and adolescents ${ }^{16-20}$ have identified SES as a determinant of diet quality. For instance, evidence from crosssectional studies in children and adolescents have reported a positive association between 
SES and fruit and vegetable intake, ${ }^{17} \quad 18 \quad 21$ and conversely, lower levels of SES have been associated with poor dietary outcomes, including a greater intake of high fat foods, ${ }^{20}$ fast foods and soft drinks. ${ }^{19}$ Studies examining the association between SES and sodium intake are scarce and inconsistent. One study in British adults found that low SES was associated with a higher intake of sodium, ${ }^{22}$ whereas in US adults, there was no association between SES and sodium intake. ${ }^{23}$ The aim of this study was to examine the association between SES and dietary sodium intake and the food sources of sodium in a nationally representative sample of Australian children aged 2-16 years.

\section{METHODS}

Study design

The 2007 Australian Children's Nutrition and Physical Activity Survey (CNPAS) was a cross-sectional survey designed to collect demographic, dietary, anthropometric and physical activity data from a nationally representative sample of children aged 2-16 years. The full details of the sampling methodology can be found elsewhere. ${ }^{24}$ Briefly, participants were recruited using a multistage quota sampling framework. The initial target quota was 1000 participants for each of the following age groups: $2-3,4-8,9-13$ and $14-16$ years $(50 \%$ boys and $50 \%$ girls), to which a 400 booster sample was later provided by the state of South Australia. The primary sampling unit was postcode and clusters of postcodes were randomly selected as stratified by state/territory and by capital city statistical division or rest of state/territory. Randomly selected clusters of postcodes ensured an equal number of participants in each age group, from each of the metro and non-metro areas within each state. Within selected postcodes, Random Digit Dialling was used to invite eligible households, that is, those with children aged 2-16 years, to participate in the study. Only one child from each household could participate in the study. The response rate of eligible children was $40 \%$. Owing to the non-proportionate nature of the sampling framework, each participant was assigned a population weighting which weighted for age, gender and region. The study was approved by the National Health and Medical Research Council registered Ethics Committees of the Commonwealth Scientific and Industrial Research Organisation and the University of South Australia. All participants or, where the child was aged < 14 years, the primary carer provided written consent. ${ }^{24}$

\section{Assessments}

Demographic and food intake data were collected during a face-to-face computer-assisted personal interview completed between February 2007 and August 2007. A three-pass $24 \mathrm{~h}$ dietary recall was used to determine all food and beverages consumed from midnight to midnight on the day prior to the interview. ${ }^{24}$
The three-pass method includes the following stages: (1) providing a quick list of all foods and beverages, (2) a series of probe questions relevant to each quick list item to gather more detailed information on the time and place of consumption, any additions to the food item, portion size and brand name and (3) finally, a recall review to validate information and make any necessary adjustments. Portion sizes were estimated using a validated food model booklet and standard household measures. To minimise error after data collection, all interviews were reviewed by study dieticians to assess for unrealistic portion sizes, inadequate detail and typing errors. The primary carer of participants aged 9 years and under provided information on dietary intake. $^{24}$

Sodium intake was calculated using the Australian nutrient composition database AUSNUT2007, specifically developed by the Food Standards Australia and New Zealand for the CNPAS. ${ }^{25}$ The food coding system used in this database has previously been described. ${ }^{26}$ Daily sodium $(\mathrm{mg})$ intake was converted to the salt equivalent (g) using the conversion 1 gram of sodium chloride (salt) $=390 \mathrm{mg}$ sodium. The reported salt intake did not include the salt added at the table or during cooking.

\section{Indicator of socioeconomic status}

Consistent with the other dietary studies in children and adolescents, we have used the level of education attained by the primary carer and household income as markers of SES. ${ }^{27}$ The highest level of education attained by the primary carer was used to define SES. Based on this, participants were grouped into one of three categories of SES: (1) high: includes those with a university/tertiary qualification, (2) mid: includes those with an advanced diploma, diploma or certificate III/IV or trade certificate and (3) low: includes those with some or no level of high school education. Parental income was used as a secondary indicator of SES. Reported parental income before tax was grouped into four categories (1) AUD $\$ 0$ to $\$ 31999$, (2) $\$ 31200$ to $\$ 51999$, (3) $\$ 52000$ to $\$ 103999$ and (4) $\geq \$ 104000$. Body weight and height were measured using standardised protocols. ${ }^{29}$ Body mass index (BMI) was calculated as body weight $(\mathrm{kg})$ divided by the square of body height $\left(\mathrm{m}^{2}\right)$. Participants were grouped into weight categories (very underweight, underweight, healthy weight, overweight, obese) using the International Obesity Task Force BMI reference cut-offs for children. ${ }^{30} 31$

\section{Statistical analysis}

Statistical analyses were completed using STATA/SE V.11 (StataCorp, College Station, Texas, USA) and PASW Statistics V.17.0 (PASW Inc, Chicago, Illinois, USA). A $p$ value of $<0.05$ was considered significant. All analyses accounted for the complex survey design using the STATA svy command, specifying the strata variable (region), cluster variable (postcode) and population weighting (age, gender and region). Descriptive statistics 
are presented as mean (SD) or n (\% weighted). Pearson correlation coefficient was used to assess the association between sodium intake, energy intake and BMI. To assess the association between SES, as defined by primary carer education level, and sodium intake, multiple regression analysis was used with adjustment for age, gender, energy intake and BMI. To further control for the effects of age, the analysis was repeated stratified by the age group (ie, $2-3 ; 4-8 ; 9-13 ; 14-16$ years). These age categories are consistent with those used in Australian dietary guidelines ${ }^{6}$. As income level is sometimes used as a marker of SES, ${ }^{13}$ the association between parental income and sodium intake was also examined, with adjustment for age, gender, energy intake and BMI. The regression coefficient $(\beta)$ with $95 \%$ $\mathrm{CI}$, corresponding p values and the coefficient of determination $\left(\mathrm{R}^{2}\right)$ are presented. In a previous analysis ${ }^{26}$ which included the same study population, we used the population proportion formula ${ }^{32}$ to calculate the contribution of sodium from submajor food group categories, as defined in the CNPAS food group coding system. ${ }^{24}$ The population proportion formula ${ }^{32}$ is outlined below:

$$
\begin{aligned}
& \text { Percentage of sodium from food group } \\
& =(\text { sum of sodium from food group }(\mathrm{mg}) \\
& \quad \text { total sum of sodium from all foods }(\mathrm{mg})) \times 100
\end{aligned}
$$

For the present study, we have utilised this list, which identifies the main sources of dietary sodium, to determine if sodium intake from the food group differs between low and high SES categories, based on primary carer education level. To do this, we calculated the mean sodium intake from each submajor food group by SES category, and compared the mean sodium of low with high SES, using an independent $t$ test.

\section{RESULTS}

Basic characteristics of the 4487 participants are listed in table 1 . As defined by parental education status, the proportion of children from low, medium and high SES backgrounds was relatively evenly distributed. Over two-thirds of children fell within the two highest income bands. There was a significant positive correlation between sodium intake and energy intake $(r=0.69$, $\mathrm{p}<0.001)$ and sodium intake and BMI $(\mathrm{r}=0.22, \mathrm{p}<0.001)$. Average daily sodium intake differed by SES (figure 1, $\mathrm{p}<0.01)$. Regression analysis indicated that low SES was associated with a $195 \mathrm{mg} /$ day (salt $0.5 \mathrm{~g} /$ day) greater intake of sodium. The association between SES and sodium intake remained after adjustment for age, gender, energy intake and BMI (table 2). When stratified by the age group, the association between sodium intake and SES remained significant between the ages of 4-13 years (table 2); however, there was no association between sodium intake and SES in 2-year-olds to 3-year-olds or in 14-year-olds to 16-year-olds (data not shown). There was no association between sodium

\begin{tabular}{|c|c|c|}
\hline Characteristic & $\begin{array}{l}\mathrm{n} \text { or } \\
\text { mean }\end{array}$ & $\begin{array}{l}\text { Per cent or } \\
\text { SD }\end{array}$ \\
\hline Male (n \%) & 2249 & 51 \\
\hline Age (years) (mean SD) & 9.1 & 4.3 \\
\hline \multicolumn{3}{|l|}{ Age group (years) (n \%) } \\
\hline $2-3$ & 1071 & 12 \\
\hline $4-8$ & 1216 & 34 \\
\hline $9-13$ & 1110 & 33 \\
\hline $14-16$ & 1090 & 21 \\
\hline \multicolumn{3}{|l|}{ Socioeconomic status $(n \%)^{*}$} \\
\hline Low SES & 1414 & 30 \\
\hline Medium SES & 1583 & 36 \\
\hline High SES & 1490 & 34 \\
\hline \multicolumn{3}{|l|}{ Parental income (n \%)† } \\
\hline$\$ 0-31999$ & 500 & 11 \\
\hline$\$ 32000-51999$ & 732 & 17 \\
\hline$\$ 52000-103999$ & 1850 & 42 \\
\hline$\$ \geq 104000$ & 1169 & 30 \\
\hline \multicolumn{3}{|l|}{ Weight status (n \%)‡ } \\
\hline Underweight & 212 & 5 \\
\hline Healthy weight & 3267 & 72 \\
\hline Overweight & 761 & 17 \\
\hline Obese & 247 & 6 \\
\hline Energy (kJ/day) (mean SD) & 8392 & 3156 \\
\hline Sodium (mg/day) (mean SD) & 2473 & 1243 \\
\hline $\begin{array}{l}\text { Salt equivalent (g/day) } \\
\text { (mean SD)§ }\end{array}$ & 6.3 & 3.1 \\
\hline \multicolumn{3}{|c|}{$\begin{array}{l}\text { *SES as defined by the highest level of education attained by the } \\
\text { primary carer. } \\
\text { †Participants with missing information for parental income ( } \mathrm{n}=236) \\
\text { excluded. } \\
\text { †Weight classification based on the International Obesity Task } \\
\text { Force BMI reference cut-offs. } 30 \text { } 31 \\
\text { §Salt equivalents (ie, sodium chloride: } 1 \mathrm{~g}=390 \mathrm{mg} \text { sodium). } \\
\text { BMI, body mass index; SES, socioeconomic status. }\end{array}$} \\
\hline
\end{tabular}

Table 1 Basic characteristics of Australian children and adolescents aged $2-16$ years $(n=4487)$

intake and parental income (data not shown); however, only $28 \%$ of children fell within the two lowest income bands (table 1). Table 3 lists those submajor food groups which contributed $>1 \%$ to the groups' total daily sodium intake. Combined, these 23 food groups accounted for $84.5 \%$ of the total daily sodium intake. Regular breads and bread rolls contributed the most sodium (13.4\%). Moderate sources of sodium, contributing more than $4 \%$ of the total sodium intake, included mixed dishes where cereal is the major ingredient (eg, pizza, hamburger, sandwich, savoury rice and noodlebased dishes), processed meat, gravies and savoury sauces, pastries, cheese and breakfast cereals and bars. Compared with children of high SES, children of low SES had a significantly greater intake of sodium from processed meat, gravies and savoury sauce, pastries, breakfast cereals and bars, potatoes and potato snacks (eg, potato crisps). The percentage difference in sodium intake in each of these categories was $46 \%, 31 \%$, 24\%, $16 \%, 39 \%$ and 46\%, respectively (table 3 ). Conversely, children of high SES background had a 


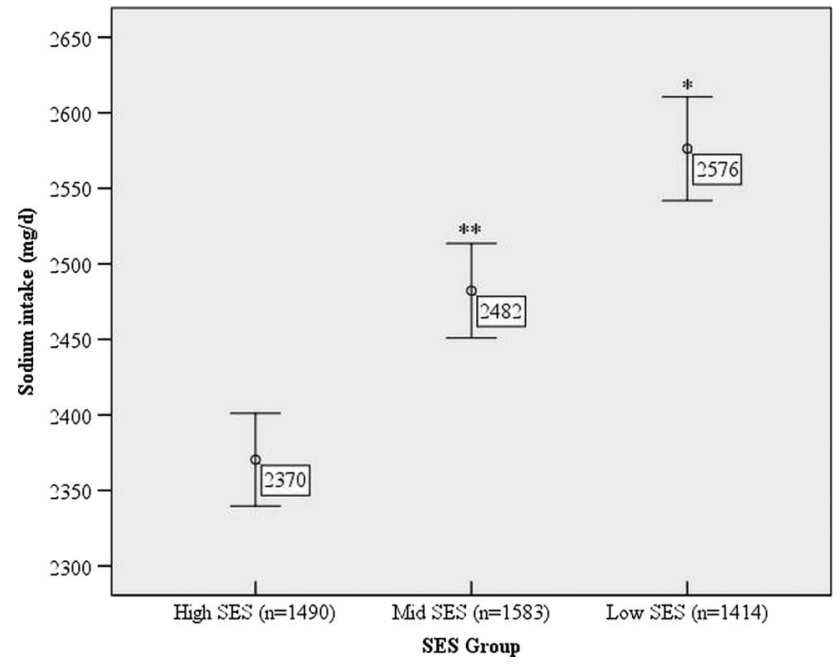

Figure 1 Mean sodium intake (mg/day) by socioeconomic group $(n=4487)^{\star}$ Significantly different from high socioeconomic status (SES) $(p<0.001) .{ }^{*}$ Significantly different from high SES $(p<0.05)$. TSES as defined by the highest level of education attained by the primary carer.

significantly greater intake of sodium from the food group containing cakes, buns, muffins, scones, cake-type desserts, and from the food group described as batterbased products (eg, pancakes and picklets). The percentage difference in sodium intake in each of these categories was $16 \%$ and $32 \%$, respectively (table 3 ).

\section{DISCUSSION}

In a nationally representative sample of Australian children aged 2-16 years, we found that children of low SES background consumed $9 \%$ more dietary sodium from food sources than those of high SES background. The inverse association between sodium intake and
SES was primarily driven by the association in children aged 4-13 years, particularly after adjustment for the important covariates age, gender, energy intake and BMI. In adult studies, low SES has been associated with more frequent consumption of high salt foods, such as soup, sauces, ready-to-eat meals, savoury seasonings, sausages and potato. ${ }^{33}$ Given the parental control over children's food choices during these years, it is likely that SES disparities in adult food choices relating to high-salt foods may filter down into children's eating practices. We found no association between SES and sodium intake in 2-year-olds to 3-year-olds and 14-year-olds to 16-year-olds. Although some evidence indicates that SES disparities in dietary patterns may be present during infancy, ${ }^{35}$ it is possible that such early differences are not seen in dietary patterns with the restricted range of food types. In the case of adolescents, as autonomy over food choices increases, other factors, such as peer influence, taste and eating away from the home ${ }^{36}$ may become more prominent determinants of dietary intake.

Using US National Health and Nutrition Examination Survey data, Mazur et $a l^{37}$ explored the association of SES, as indicated by the head of household education status and household income, on sodium intake in Hispanic children aged 4-16 years. Interestingly, in this study, lower levels of education were associated with lower sodium intake. ${ }^{37}$ This is in contrast to our own findings as well as past studies, which generally link lower SES to overall poorer dietary outcomes. ${ }^{13} \mathrm{We}$ found no association between sodium intake and level of income; however, low-income bands were underrepresented. This is in contrast to the findings in Hispanic children, where low household income was associated with a greater intake of dietary sodium. ${ }^{37}$ In a New Zealand food survey, low-cost 'home brand'-labelled

Table 2 Association between socioeconomic status (SES) and dietary sodium intake (390 mg/day) (1 g/day salt) in Australian children and adolescents aged $2-16$ years $(n=4487)^{\star} \dagger$

\begin{tabular}{|c|c|c|c|c|c|c|}
\hline \multirow{3}{*}{ Variable } & \multicolumn{2}{|c|}{ Total sample ( $n=4$ 487) } & \multicolumn{4}{|l|}{ Age group } \\
\hline & \multirow[b]{2}{*}{ B $(95 \% \mathrm{Cl})$} & \multirow[b]{2}{*}{ p Value } & \multicolumn{2}{|c|}{ 4-8 years $(n=1216)$} & \multicolumn{2}{|c|}{$9-13$ years $(n=1110)$} \\
\hline & & & $\overline{\beta(95 \% \mathrm{CI})}$ & $\overline{p \text { Value }}$ & $\beta(95 \% \mathrm{CI})$ & p Value \\
\hline \multicolumn{7}{|l|}{ Unadjusted } \\
\hline \multicolumn{7}{|c|}{ High SES (reference) } \\
\hline Medium SES & $0.3(0.03$ to 0.5$)$ & 0.03 & $0.2(-0.1$ to 0.6$)$ & 0.17 & $0.2(-0.2$ to 0.6$)$ & 0.319 \\
\hline \multirow[t]{2}{*}{ Low SES } & 0.5 (0.3 to 0.8$)$ & $<0.001$ & $0.5(0.1$ to 1.0$)$ & 0.02 & $0.5(-0.02$ to 1.0$)$ & 0.06 \\
\hline & $R^{2}=0.004$ & $<0.01$ & $R^{2}=0.008$ & 0.05 & $R^{2}=0.004$ & 0.16 \\
\hline \multicolumn{7}{|l|}{ Adjusted§ } \\
\hline \multicolumn{7}{|c|}{ High SES (reference) } \\
\hline Medium SES & $0.2(0.01$ to 0.4$)$ & 0.04 & $0.2(-0.1$ to 0.4$)$ & 0.13 & $0.2(-0.2$ to 0.6$)$ & 0.23 \\
\hline \multirow[t]{2}{*}{ Low SES } & $0.5(0.2$ to 0.7$)$ & $<0.001$ & $0.6(0.2$ to 0.9$)$ & 0.001 & $0.6(0.1$ to 1.0$)$ & 0.01 \\
\hline & $R^{2}=0.49$ & $<0.001$ & $\mathrm{R}^{2}=0.37$ & $<0.001$ & $R^{2}=0.36$ & $<0.001$ \\
\hline
\end{tabular}


Table 3 Dietary sources of sodium intake listed by their contribution to intake for the group and mean daily sodium intake by food group, by socioeconomic group*

\begin{tabular}{|c|c|c|c|c|c|}
\hline \multirow{2}{*}{ Food group } & \multirow{2}{*}{$\begin{array}{l}\text { Total sample }(n=4487) \\
\text { Percentage of } \\
\text { contribution to total } \\
\text { daily sodium intake }\end{array}$} & \multicolumn{4}{|l|}{ SES groupt } \\
\hline & & $\begin{array}{l}\text { Low (n 1414) } \\
\text { Mean sodium } \\
\text { (SD) mg/day }\end{array}$ & $\begin{array}{l}\text { Mid (n 1583) } \\
\text { Mean sodium } \\
\text { (SD) mg/day }\end{array}$ & $\begin{array}{l}\text { High (n 1490) } \\
\text { Mean sodium } \\
\text { (SD) mg/day }\end{array}$ & p Value \\
\hline Regular breads and bread rolls & 13.4 & $340(315)$ & $330(300)$ & $324(317)$ & 0.26 \\
\hline $\begin{array}{l}\text { Mixed dishes where cereal is the } \\
\text { major ingredient }\end{array}$ & 8.7 & $214(514)$ & $256(616)$ & $172(445)$ & 0.07 \\
\hline Processed meat§ & 7.6 & $216(464)$ & $180(403)$ & $168(368)$ & 0.02 \\
\hline Gravies and savoury sauces & 6.5 & $182(385)$ & $166(395)$ & $139(354)$ & 0.01 \\
\hline Pastries" & 4.9 & $135(400)$ & $120(352)$ & 109 (345) & 0.03 \\
\hline Cheese & 4.6 & $114(209)$ & $110(190)$ & $116(186)$ & 0.80 \\
\hline Breakfast cereals and bars & 4.2 & $113(176)$ & $101(166)$ & $97(161)$ & 0.03 \\
\hline Dairy milk & 3.9 & 95 (106) & 94 (103) & $100(98)$ & 0.25 \\
\hline $\begin{array}{l}\text { Herbs, spices, seasonings and } \\
\text { stock cubes }\end{array}$ & 3.7 & $114(482)$ & $75(246)$ & $90(301)$ & 0.31 \\
\hline Sausages, Frankfurts and Saveloys & 2.9 & 79 (259) & $74(136)$ & $61(201)$ & 0.07 \\
\hline $\begin{array}{l}\text { Mixed dishes where poultry/game is } \\
\text { the major component }\end{array}$ & 2.6 & $79(268)$ & 59 (194) & $60(238)$ & 0.09 \\
\hline Soup (prepared, ready to eat) & 2.6 & $51(288)$ & 74 (379) & $65(282)$ & 0.25 \\
\hline $\begin{array}{l}\text { English-style muffins, flat breads } \\
\text { and savoury sweet breads }\end{array}$ & 2.4 & $55(158)$ & $58(180)$ & $67(181)$ & 0.17 \\
\hline $\begin{array}{l}\text { Cakes, buns, muffins, scones, } \\
\text { cake-type desserts }\end{array}$ & 2.3 & 54 (153) & $52(144)$ & 68 (176) & 0.02 \\
\hline Savoury biscuits & 2.2 & $49(136)$ & $57(147)$ & $57(152)$ & 0.34 \\
\hline $\begin{array}{l}\text { Yeast, yeast, vegetable and meat } \\
\text { extracts }\end{array}$ & 2.0 & $47(117)$ & $55(143)$ & $45(108)$ & 0.70 \\
\hline Potatoes†† & 1.9 & $53(128)$ & $51(127)$ & $38(106)$ & 0.01 \\
\hline Batter-based products $¥ \ddagger$ & 1.7 & 38 (161) & 37 (150) & $50(180)$ & 0.05 \\
\hline Potato snacks & 1.7 & 51 (149) & $40(121)$ & 35 (125) & 0.03 \\
\hline Pasta and pasta products & 1.4 & $35(142)$ & $32(130)$ & $35(138)$ & 0.89 \\
\hline Sweet biscuits & 1.2 & $29(64)$ & $33(72)$ & $27(62)$ & 0.61 \\
\hline $\begin{array}{l}\text { Mixed dishes where beef, veal or } \\
\text { lamb is the major component }\end{array}$ & 1.1 & $32(175)$ & $21(116)$ & $28(56)$ & 0.53 \\
\hline $\begin{array}{l}\text { Mature legumes and pulse products } \\
\text { and dishes }\end{array}$ & 1.0 & $21(149)$ & $21(137)$ & $35(258)$ & 0.12 \\
\hline \multicolumn{6}{|c|}{$\begin{array}{l}\text { *Includes those submajor food group categories that contribute }>1 \% \text { of sodium to daily intake ambiguous. } \\
\text { †SES as defined by the highest level of education attained by the primary carer. } \\
\text { †Means are compared between low and high SES groups using independent } t \text { test. } \\
\text { §Includes ham, bacon and processed delicatessen meat. } \\
\text { ๆlncludes pasta sauces and casserole bases. }\end{array}$} \\
\hline
\end{tabular}

food products were found to contain greater quantities of sodium than the more expensive branded food products. ${ }^{38}$ The impact of income on sodium intake in Australian children remains unclear and further research is required.

Previous studies in children have reported socioeconomic differences in the consumption of certain food groups. ${ }^{39}$ For example, in European children of low SES background, greater intake of starchy foods, meat products, savoury snacks such as hamburgers, sugar and confectionery, pizza, desserts and soft drinks have been reported. ${ }^{39}{ }^{40}$ In the present study, those food groups which were found to contribute more sodium to the diets of low SES children tended to include convenience style foods (ie, pies/sausage rolls; savoury sauce and casserole base sauces; fried prepared potato; processed meat and potato snacks). Comparably, children of high SES background consumed greater amounts of sodium from cake-type and baked-type products. However, a significant amount of sodium in baked products can be in the form of sodium bicarbonate rather than sodium chloride. Sodium bicarbonate, unlike sodium chloride, has not been directly associated with adverse blood pressure outcomes. ${ }^{41}$

With reference to sodium intake data by age group ${ }^{5}$ and in comparison to the recommended daily upper limit of 
sodium, ${ }^{6}$ it is evident that Australian children of all ages across all SES backgrounds are consuming too much dietary sodium. However, for the first time, our findings indicate that socioeconomic disparities exist in sodium intake in Australian children aged 9-13 years. To reduce sodium intake in children, a comprehensive approach is required: first, targeting food policy to encourage product reformulation of lower sodium food products across all price ranges within the food supply. Second, consumer education and awareness campaigns that encourage food choices which are based on fresh products with minimal processing; this may require strategies that equip parents with enhanced food preparation skills and knowledge of the 'hidden' salt added to many commonly eaten processed foods. Furthermore, it is apparent that these strategies need to reach lower SES groups.

The major strengths of this study include the use of a large nationally representative sample of Australian children, with a comprehensive and standardised collection of dietary intake. Limitations of the study include the use of a 24-h dietary recall to assess sodium intake. First, this method fails to capture the amount of salt derived from salt added at the table and during cooking and therefore is likely to underestimate the true value of salt intake. $^{42}$ The majority $(77 \%)$ of dietary sodium consumed is from salt added to processed foods, while a smaller amount $(11 \%)$ has been found to be derived from salt added at the table and during cooking. ${ }^{43}$ In the present study, the higher intake of sodium reported in children from low SES background is attributable to differences in sodium intake from food sources only. In a previous analysis of these data, we found that children from low SES background $(33 \%)$ were more likely to report adding salt at the table than children from high SES $(25 \%){ }^{26}$ Thus, it is likely that children of low SES background are consuming greater amounts of total daily sodium than reported in the present analysis. Second, the assessment of sodium intake is limited by the quality of food composition databases, which may not capture the variation in sodium content of different brand products within each food group. 4244

In summary, the findings of higher salt intake from food sources in children of lower SES background, within a nationally representative sample, provide focus for concern regarding salt-related disease across the life course. This socioeconomic patterning of salt intake may, in turn, influence the SES disparity seen in hypertension and cardiovascular risk in adulthood. To reduce the socioeconomic inequalities in health, interventions need to begin early in life and should include product reformulation of lower sodium food products across all price ranges, as well as consumer education and awareness campaigns which reach low SES groups.

Contributors The author's responsibilities were as follows-CAG, KJC, LJR and CAN designed the research; CAG performed the statistical analysis and wrote the manuscript and is also the guarantor of the paper; LJR, KJC and
CAN helped with data interpretation, revision of the manuscript and provided significant consultation. All authors have read and approved the final manuscript.

Funding This work was supported by a postgraduate scholarship from the Heart Foundation of Australia PP 08M 4074.

Competing interests All authors have completed the Unified Competing Interest form at www.icmje.org/coi_disclosure.pdf (available on request from the corresponding author) and declare: Carley Grimes had financial support in the form of a postgraduate scholarship from the Heart Foundation, Australia for the submitted work and had no financial relationships with any organisations that might have an interest in the submitted work in the previous 3 years, no other relationships or activities that could appear to have influenced the submitted work. Karen Campbell had no support from any organisation for the submitted work; no other relationships or activities that could appear to have influenced the submitted work. Caryl Nowson has received research funds from Meat \& Livestock Australia; National Health and Medical Research Council, Wicking Foundation, National Heart Foundation, Australia, Helen MacPerhson Smith Trust and Red Cross Blood Bank. These payments are unrelated to the submitted work. Lynn Riddell has received research funds from Meat \& Livestock Australia. These payments are unrelated to the submitted work.

\section{Patient consent Obtained.}

Ethics approval National Health and Medical Research Council registered Ethics Committees of Commonwealth Scientific and Industrial Research Organisation and the University of South Australia.

Provenance and peer review Not commissioned; externally peer reviewed.

Data sharing statement No additional data are available.

\section{REFERENCES}

1. Dickinson BD, Havas S. Reducing the population burden of cardiovascular disease by reducing sodium intake. Arch Intern Med 2007;167:1460-68.

2. He FJ, MacGregor GA. Importance of salt in determining blood pressure in children meta-analysis of controlled trials. Hypertension 2006;48:861-9.

3. He FJ, Marrero NM, MacGregor GA. Salt and blood pressure in children and adolescents. J Hum Hyperten 2008;22:4-11.

4. Brown IJ, Tzoulaki I, Candeias V, et al. Salt intakes around the world: implications for public health. Int J Epidemiol 2009;38:791-813.

5. Department of Health and Ageing, Australian Food and Grocery Council, Department of Agriculture Fisheries and Forestry. 2007 Australian National Children's Nutrition and Physical Activity Surveymain findings. Canberra: Commonwealth of Australia, 2008. http://www. health.gov.au/internet/main/publishing.nst/content/66596E8FC68FD 1A3CA2574D50027DB86/\$File/childrens-nut-phys-survey.pdf (accessed 12 Jun 2012)

6. National Health and Medical Research Council. Nutrient reference values for Australia and New Zealand. Canberra:Australian Government. Department of Health and Ageing, 2006. http://www. nhmrc.gov.au/_files_nhmrc/publications/attachments/n35.pdf (accessed 12 Jun 2012)

7. Chen X, Wang Y. Tracking of blood pressure from childhood to adulthood-a systematic review and meta-regression analysis. Circulation 2008;117:3171-80.

8. Toschke AM, Kohl L, Mansmann U, et al. Meta-analysis of blood pressure tracking from childhood to adulthood and implications for the design of intervention trials. Acta Paediatrica 2010;99:24-9.

9. Kaplan GA, Keil JE. Socioeconomic factors and cardiovascula disease: a review of the literature. Circulation 1993;88:1973-8.

10. Rosengren A, Subramanian SV, Islam S, et al. Education and risk for acute myocardial infarction in 52 high, middle and low-income countries: INTERHEART case-control study. Heart 2009;95:2014-22.

11. Loucks EB, Lynch JW, Pilote L, et al. Life-course socioeconomic position and incidence of coronary heart disease: the Framingham Offspring Study. Am J Epidemiol 2009;169:829-36.

12. Pollitt RA, Rose KM, Kaufman JS. Evaluating the evidence for models of life course socioeconomic factors and cardiovascular outcomes: a systematic review. BMC Public Health 2005;5:7.

13. Darmon N, Drewnowski A. Does social class predict diet quality? Am J Clin Nutr 2008;87:1107-17. 
14. Giskes K, Turrell G, Patterson C, et al. Socio-economic differences in fruit and vegetable consumption among Australian adolescents and adults. Public Health Nutr 2002;5:663-9.

15. Hulshof KFAM, Brussaard JH, Kruizinga AG, et al. Socio-economic status, dietary intake and 10 y trends: the Dutch National Food Consumption Survey. Eur J Clin Nutr 2003;57:128-37.

16. Ambrosini GL, Oddy $\mathrm{WH}$, Robinson $\mathrm{M}$, et al. Adolescent dietary patterns are associated with lifestyle and family psycho-social factors. Public Health Nutr 2009;12:1807-15.

17. Haapalahti M, Mykkanen H, Tikkanen S, et al. Meal patterns and food use in 10- to 11-year old Finnish children. Public Health Nutr 2002;6:365-70.

18. Neumark-Sztainer D, Wall M, Perry C, et al. Correlates of fruit and vegetable intake among adolescents findings from project EAT. Prev Med 2003;37:198-208.

19. Utter J, Denny S, Crengle S, et al. Socio-economic differences in eating-related attitudes, behaviours and enviornments of adolescents. Public Health Nutr 2010;14:629-34.

20. Wardle J, Jarvis MJ, Steggles N, et al. Socioeconomic disparities in cancer-risk behaviours in adolescence: baseline results from the Health and Behaviour in Teenagers Study (HABITS). Prev Med 2003;36:721-30.

21. Dubois L, Farmer A, Girard M, et al. Demographic and socio-economic factors related to food intake and adherence to nutritional recommendations in a cohort of pre-school children. Public Health Nutr 2011;14:1096-104.

22. Bates CJ, Prentice A, Cole TJ, et al. Micronutrients: highlights and research challenges from the 1994-5 National Diet and Nutrition Survey of people aged 65 years and over. Brit J Nutr 1999;82:7-15.

23. Gerber AM, James SA, Ammerman AS, et al. Socioeconomic status and electrolyte intake in black adults: the Pitt country Study. Am J Public Health 1991;81:1608-12.

24. Department of Health and Ageing. User Guide 2007 Australian National Children's Nutrition and Physical Activity Survey. Canberra:2010. http://www.health.gov.au/internet/main/publishing. nsf/Content/AC3F256C715674D5CA2574D60000237D/\$File/ user-guide-v2.pdf (accessed 10 May 2012)

25. Food Standards Australian and New Zealand (Internet). Canberra: Food Standards Australia and New Zealand; (cited Jan 23 2009). http://www.foodstandards.gov.au/consumerinformation/ausnut2007/ (accessed 16 Nov 2012)

26. Grimes CA, Campbell KJ, Riddell LJ, et al. Sources of sodium in Australian children's diets and the effect of the application of sodium targets to food products to reduce sodium intake. Br J Nutr 2011;105:468-77.

27. Cameron AJ, Ball K, Pearson N, et al. Socioeconomic variation in diet and activity-related behaviours of Australian children and adolescents aged 2-16 years. Pediatr Obes 2010;7:329-42.

28. Golley RK, Hendrie GA, McNaughton SA. Scores on the dietary guideline index for children and adolescents are associated with nutrient intake and socio-economic position but not adiposity. J Nutr 2011;141:1340-7.
29. Marfell-Jones M, Olds T, Stewart A, et al. International standards for anthropometric assessment. Potchefstroom, South Africa: International standards for anthropometric assessment, 2006.

30. Cole TJ. Establishing a standard definition for child overweight and obesity worldwide: international survey. Br Med J 2000;320:1-6.

31. Cole TJ, Flegal KM, Nicholls D, et al. Body mass index cut offs to define thinness in children and adolescents: international survey. Br Med J 2007;335:194-7.

32. Krebs-Smith SM, Kott PS, Guenther PM. Mean proportion and population proportion: two answers to the same question? J Am Diet Assoc 1989;89:667-72.

33. Purdy J, Armstrong G, Mcllveen $\mathrm{H}$. The influence of socio-economic status on salt consumption in Northern Ireland. Int $\mathrm{J}$ Consum Stud 2002:26:71-80.

34. Van der Veen JE, Graaf CD, Van Dis SJ, et al. Determinants of salt use in cooked meals in the Netherlands: attitudes and practices of food preparers. Eur J Clin Nutr 1999:53:388-94.

35. Okubo H, Miyake Y, Sasaki S, et al. Dietary patterns in infancy and their associations with maternal socio-economic and lifestyle factors among 758 Japanese mother-child pairs: the Osaka Maternal and Child Health Study. Matern Child Nutr 2012;8.doi:10.1111/j. 740-8709.2012.00403.x

36. Story M, Neumark-Sztainer D, French S. Individual and environmental influences on adolescent eating behaviours. J Am Diet Assoc 2002;102:S40-51.

37. Mazur RE, Marquis GS, Jensen HH. Diet and food insufficiency among Hispanic youths: acculturation and socioeconomic factors in the third National Health and Nutrition Examination Survey. Am J Clin Nutr 2003;78:1120-7.

38. Monro D, Young L, Wilson J, et al. The sodium content of low cost and private label foods; implications for public health. J NZ Diet Assoc 2004;58:4-10.

39. Lioret S, Dubuisson C, Dufour A, et al. Trends in food intake in French children from 1999 to 2007: results from the INCA (etude Individuelle Nationale des Consommations Alimentaires) dietary surveys. Br J Nutr 2010;103:585-601.

40. Sausenthaler S, Standl M, Buyken A, et al. Regional and socio-economic differences in food, nutrient and supplement intake in school-age children in Germany: results from the GINIplus and the LISAplus studies. Public Health Nutr 2011;10:1724-35.

41. McCarty MF. Should we restrict chloride rather than sodium? Med Hypotheses 2004;63:138-48.

42. Loria CM, Obarzanek E, Ernst ND. The dietary guidelines: surveillance issues and research needs. Choose and prepare foods with less salt: dietary advice for all Americans. J Nutr 2001;131:536S-51S.

43. Mattes RD, Donnelly D. Relative contributions of dietary sodium sources. J Am Coll Nutr 1991;10:383-93.

44. World Health Organization. Creating an enabling enviornment for population-based salt reduction strategies. UK: World Health Organization, 2010. http://whqlibdoc.who.int/publications/2010/ 9789241500777_eng.pdf. (accessed 10 Jun 2012) 